\title{
Actinomicosis en el hueso temporal. Reporte de un caso pediátrico
}

\author{
Actinomycosis in temporal bone. A pediatric case report
}

\author{
Dra. Lucía V. Fernández ${ }^{a}$ Dra. Elena Arias ${ }^{b}$,Dra. Daniela Cohen ${ }^{b}$ y Dra. Roxana Spini ${ }^{b}$
}

\begin{abstract}
RESUMEN
La actinomicosis es una infección causada por un bacilo anaerobio Gram-positivo, filamentoso, ramificado, no esporulado. Integra la flora habitual de la orofaringe y coloniza transitoriamente el tracto gastrointestinal, genital femenino y el árbol bronquial. Es poco frecuente en el hueso temporal. Por su semejanza a un hongo, es difícil su reconocimiento, lo que hace necesaria la sospecha clínica para obtener los cultivos apropiados en condiciones anaeróbicas en forma prolongada. Los hallazgos microscópicos típicos incluyen necrosis con gránulos de azufre amarillento y la presencia de filamentos que se asemejan a infecciones fúngicas. El tratamiento requiere de elevadas y prolongadas dosis de antibiótico con penicilina o amoxicilina, entre 6 y 12 meses. La duración de la terapia antimicrobiana podría ser reducida en pacientes que han sido operados quirúrgicamente. Se presenta, a continuación, un caso clínico de actinomicosis en el hueso temporal en un paciente pediátrico que requirió tratamiento quirúrgico para su resolución.

Palabras clave: actinomicosis, otitis media crónica, mastoiditis, mastoidectomía.
\end{abstract}

\begin{abstract}
Actinomycosis is an infection caused by a Gram-positive, filamentous anaerobic bacillus. Mainly belonging to the human commensal flora of the oropharynx, it normally colonizes the human digestive and genital tracts and the bronchial tree. It is slightly frequent in the temporal bone. Bacterial cultures and pathology are the cornerstone of diagnosis, but particular conditions are required in order to get the correct diagnosis. Prolonged bacterial cultures in anaerobic conditions are necessary to identify the bacterium and typical microscopic findings include necrosis with yellowish sulfur granules and filamentous Gram-positive fungal-like pathogens. Patients with actinomycosis require prolonged (6- to 12-month) high doses of penicillin $\mathrm{G}$ or amoxicillin, but the duration of antimicrobial therapy could probably be shortened in patients in whom optimal surgical resection of infected tissues has been performed. A pediatric patient with actinomycosis in temporal bone who needed surgery resolution is reported.

Key words: actinomycosis, chronic otitis media, mastoiditis, mastoidectomy.
\end{abstract}

a. Residencia de Otorrinolaringología Infantil.

b. División de Otorrinolaringología.

Hospital General de Niños Pedro de Elizalde,

Ciudad Autónoma de Buenos Aires, Argentina.

Correspondencia:

Dra. Lucía V. Fernández: lucifernandez1986@gmail.com

Financiamiento: Ninguno.

Conflicto de intereses: Ninguno que declarar.

Recibido: 2-6-2020

Aceptado: 30-9-2020 http: / / dx.doi.org/10.5546/aap.2021.e153

Cómo citar: Fernández LV, Arias E, Cohen D, Spini R. Actinomicosis en el hueso temporal. Reporte de un caso pediátrico. Arch Argent Pediatr 2021;119(2):e153-e157.

\section{INTRODUCCIÓN}

La actinomicosis es una infección causada por un bacilo anaerobio Gram-positivo, filamentoso, ramificado, no esporulado, ${ }^{1}$ que integra la flora habitual de la orofaringe y coloniza transitoriamente el tracto gastrointestinal (estómago, colon), genital femenino (vagina) y árbol bronquial. ${ }^{2}$ El origen de la infección es endógeno y no existen casos documentados de transmisión interhumana. Sus características, que lo asemejan a un hongo en su apariencia y conducta, tornan difícil su reconocimiento, lo que hace necesaria la sospecha clínica para obtener los cultivos apropiados. Las poblaciones con limitado acceso al cuidado médico y odontológico presentan mayor riesgo de adquirir la enfermedad.

La infección es producida, principalmente, por Actinomyces israelii. Se desarrolla a partir de una disrupción de las barreras mucosas y puede diseminarse por contigüidad, por vía hematógena y/o linfática. Compromete tres regiones anatómicas principales: orocervicofacial, torácica y abdominal. La anatomía patológica evidencia focos purulentos rodeados de fibrosis densa, abscesos ricos en macrófagos, células plasmáticas, eosinófilos y fibroblastos.

\section{CASO CLÍNICO}

Paciente de 7 años de edad, masculino, que ingresó con diagnóstico de mastoiditis aguda del oído derecho (OD). Fue derivado por la mala respuesta al tratamiento antibiótico endovenoso con ceftriaxona y clindamicina en su séptimo día.

Al momento del examen físico de ingreso, se constató buen estado general y nutricional, afebril. En el examen otorrinolaringológico, presentaba desplazamiento del pabellón auricular derecho hacia delante, eritema y borramiento 
del pliegue retroauricular. Oído medio ocupado. Presencia de múltiples caries y mal estado de las piezas dentarias, por lo que fue evaluado por Odontología. El resto del examen físico era normal. Negaba antecedentes personales y familiares de relevancia.

Se realizó una miringotomía amplia con muestras para el cultivo de gérmenes comunes y reacción en cadena de la polimerasa (polymerase chain reaction; $P C R$, por sus siglas en inglés) para tuberculosis: negativas. Anatomía Patológica informó inflamación crónica en actividad. Recibió tratamiento con ceftriaxona, clindamicina y corticoides por 7 días, con buena respuesta. Continuó el tratamiento ambulatorio con ciprofloxacina y clindamicina por vía oral (VO).
Control a los 7 días: con empeoramiento clínico sin haber interrumpido el tratamiento. Presentaba absceso retroauricular derecho. Otomicroscopía: atelectasia central con perforación atical pequeña, ocupación en la caja timpánica. Análisis de laboratorio: glóbulos blancos (GB), $11940 / \mathrm{mm}^{3}$ (0/60/0/2/33/7); hemoglobina: 11,8 g/ dl; hematocrito: el $36 \%$; plaquetas: $273000 / \mathrm{mm}^{3}$; hepatograma normal; proteínas totales: $6,87 \mathrm{~g} / \mathrm{dl}$; albúmina: 4,25 g/dl; proteinograma normal; proteína $C$ reactiva (PCR): 0,61. Se realizó una tomografía de ambos peñascos, que evidenció el OD ocupado por una imagen de densidad de partes blandas homogénea en la caja timpánica, ático y mastoides (Figura 1). La audiometría constató hipoacusia conductiva moderada derecha con diferencia de 35-40 db (Figura 2).

FIGURA 1. Tomografía de peñasco del oído derecho, corte coronal. A: mastoides ocupado por material de densidad de partes blandas. B: ático, mesotímpano e hipotímpano ocupado por material de densidad de partes blandas. Cadena osicular difícil de visualizar

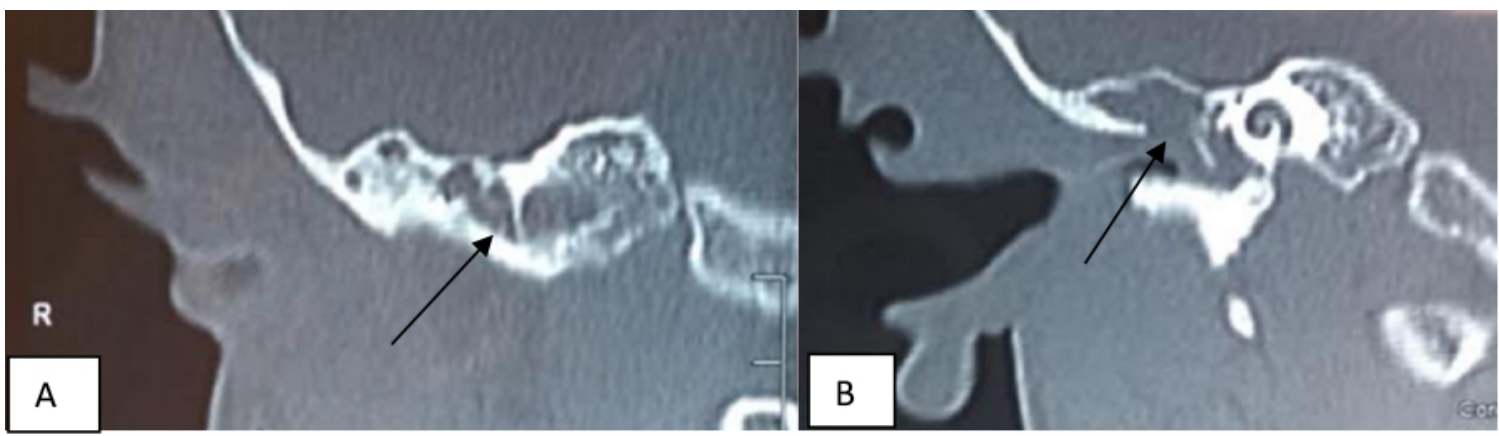

Figura 2. A. Audiometría tonal prequirúrgica: hipoacusia conductiva moderada del oído derecho. B. Audiometría tonal posquirúrgica: hipoacusia conductiva moderada-grave del oído derecho
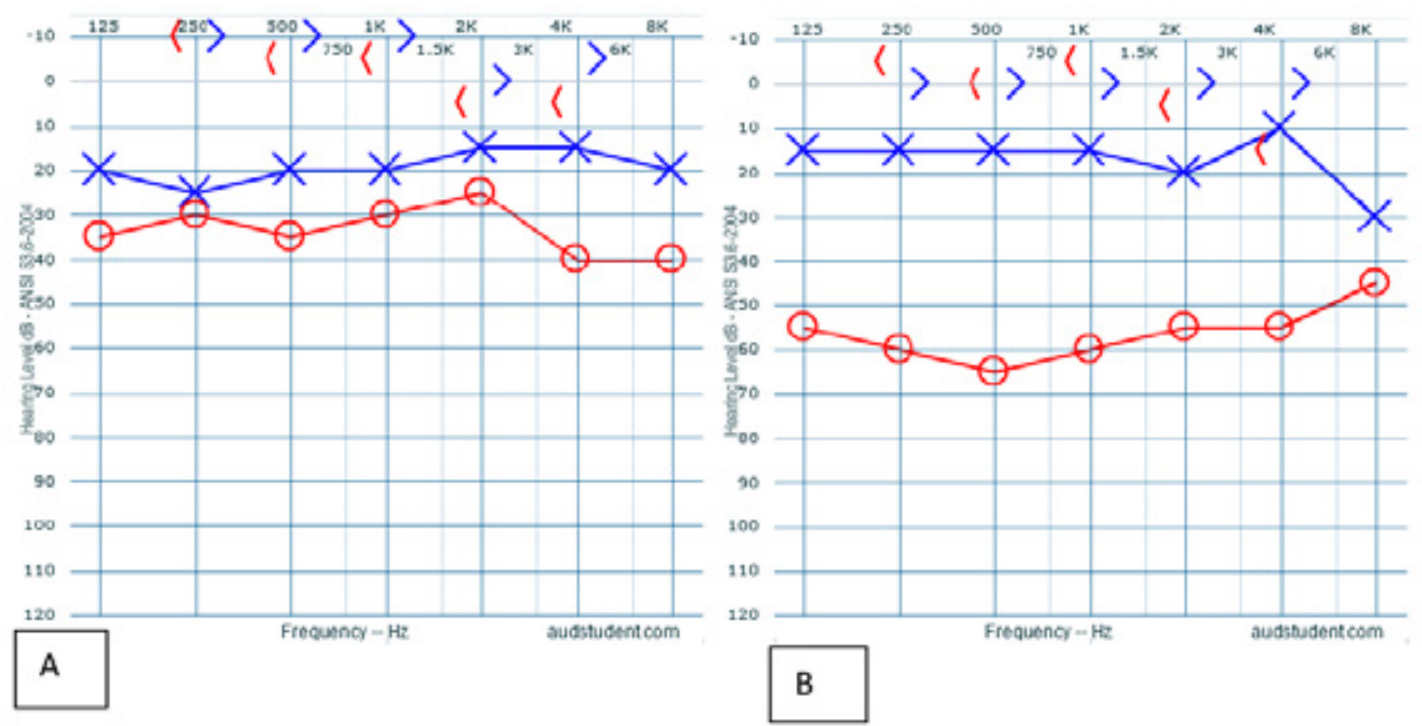
Se decidió la intervención quirúrgica. Durante la cirugía, se observó la presencia de material de aspecto pastoso y coloración parduzca, con abundante tejido de granulación en el antro, el ático y el mesotímpano. Cadena osicular con martillo indemne, apófisis larga del yunque erosionada y estribo envuelto en tejido de granulación. En mastoides, se visualizó una fístula en la tabla externa que comunicaba con tejidos blandos (Figura 3). Se enviaron muestras para anatomía patológica y cultivo.

En el posquirúrgico inmediato, presentó celulitis en el dorso paramedial derecho (escápula derecha). Se realizaron dos hemocultivos, tres lavados gástricos, serologías para hepatitis $\mathrm{A}, \mathrm{B}$, $C$, y rubéola, que fueron negativas. Las serologías para citomegalovirus y virus de Epstein-Barr fueron positivas. $P C R$ para tuberculosis, negativa; radiografía de tórax, normal; prueba cutánea de derivado proteico purificado (purified protein derivative; $P P D$, por sus siglas en inglés), negativa; virus de la inmunodeficiencia humana (human immunodeficiency virus; HIV, por sus siglas en inglés), negativo; inmunoglobulinas G, M, E y A y poblaciones linfocitarias, normales.

Por presentar, al tercer día posquirúrgico, signos de flogosis e induración en la herida quirúrgica, se modificó el esquema antibiótico

Figura 3. A. Apertura del antro (fecha negra). Conducto auditivo externo (CAE) (flecha blanca).

B, C, D. Antro: se visualiza secreción parduzca, grisácea (fecha negra) (aspecto caseoso). Se envía a cultivo de gérmenes comunes, hongos y tuberculosis. Se envía a anatomía patológica.

E, F. Mastoidectomía (flecha negra). Fístula de tabla externa de mastoides que comunica con el tejido subcutáneo (flecha blanca)
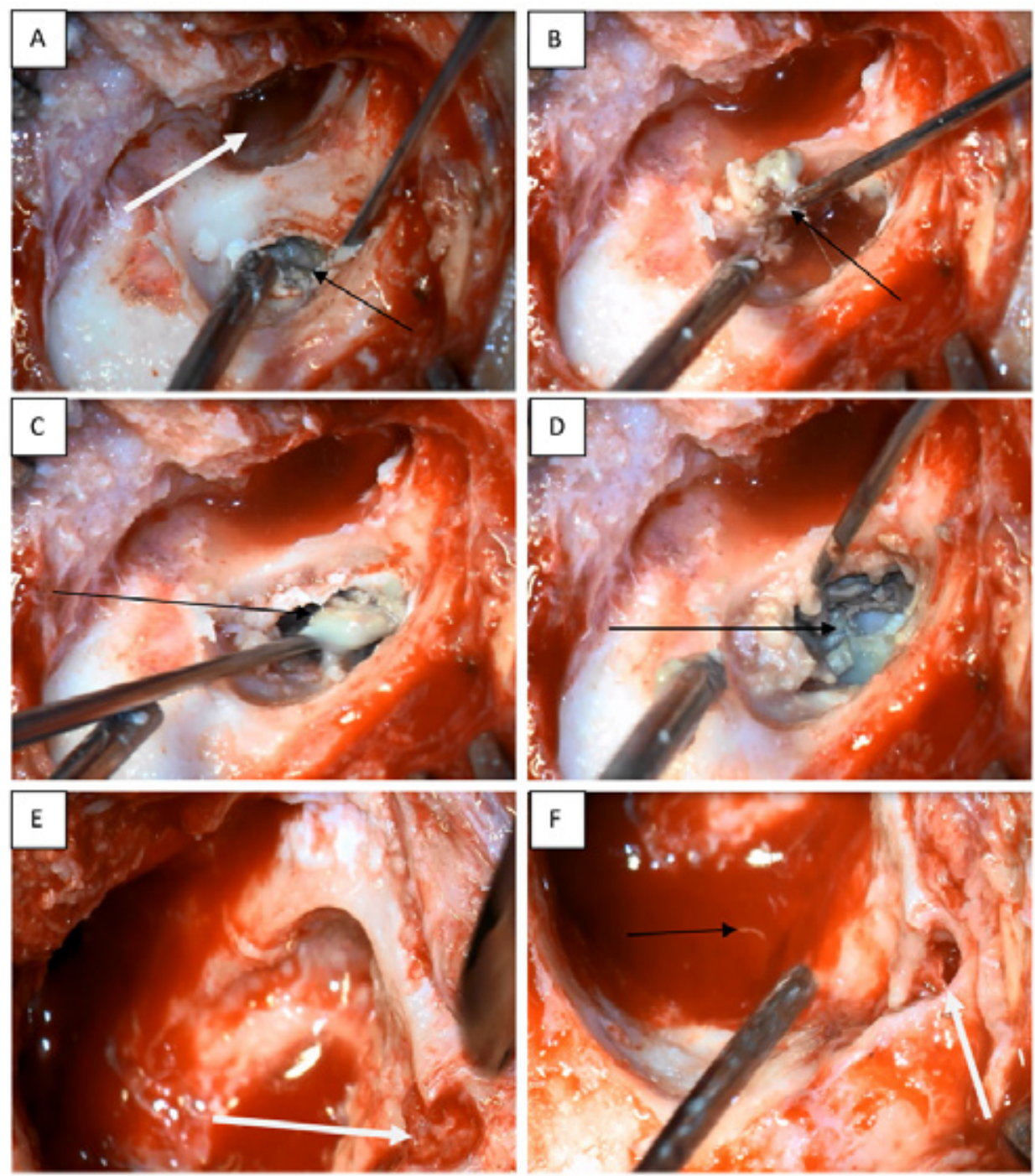
a piperacilina-tazobactam endovenosos, clindamicina endovenosa (día 10) y suspendió la ceftriaxona endovenosa (día 10). Anatomía Patológica describió fragmentos de tejido adiposo con leves-moderados infiltrados inflamatorios mononucleares acompañados por escasos neutrófilos. Material fibrohemático y necrótico compatibles con inflamación crónica en actividad. Cultivo Gram-positivo para Actinomyces europaeus. Inició el tratamiento antibiótico con penicilina G sódica a razón de 300000 U / kg / día endovenosas por tres semanas, con buena evolución, y se suspendió el último esquema antibiótico indicado. Total de días internado: 44 . Completó el tratamiento ambulatorio por tres semanas más con penicilina por VO. No se constató recidiva luego de dos años.

\section{DISCUSIÓN}

Actinomyces spp. son un grupo de bacilos Gram-positivos anaerobios y filamentosos, que pertenecen a la flora habitual de la orofaringe, el tracto gastrointestinal y el tracto urogenital. ${ }^{2}$ Son prevalentes en las grietas gingivales, criptas tonsilares y piezas dentales cariadas, y son muy poco frecuentes en el hueso temporal. ${ }^{3} \mathrm{La}$ permeabilidad de la trompa de Eustaquio es condición necesaria para el compromiso ótico a partir de la cavidad oral. ${ }^{4}$ Es considerada, principalmente, una infección endógena que se desencadena por una lesión de la mucosa.

Se han descrito más de 30 tipos de especies de Actinomyces; Actinomyces israelii es la más aislada. ${ }^{5}$ Sin embargo, otras especies, como A. odontolyticus, A. turicensis, A. viscosus, A. bovis, A. naeslundii, A. meyeri, A. europaeus y $A$. radingae, también pueden causar infecciones que involucran el tracto digestivo y urinario, la piel, los genitales y el pulmón, así como también el oído, la nariz y la garganta. ${ }^{6}$

Fueron descritas por primera vez por Beck en 1906 y Chang et al., en 1993. Las complicaciones intracerebrales pueden ocurrir aun en los pacientes tratados con antibióticos. ${ }^{7}$ En el inicio, Actinomyces spp. se agruparon taxonómicamente como un hongo, ${ }^{8,9}$ lo que explica su nomenclatura engañosa original por cierta semejanza en la formación de una red micelial y por su poder de ramificación. ${ }^{6}$ Actualmente, se agrupan dentro de las micobacterias por la presencia de ácido murámico en su pared, por carecer de mitocondrias y de membrana nuclear, por reproducirse por fisión y ser sensibles al tratamiento con penicilina, con mala respuesta a los antifúngicos. ${ }^{10}$ Son fagocitadas por las células del huésped, por lo que se definen como un parásito intracelular facultativo. Imitan otros procesos infecciosos, como osteomielitis, enfermedad granulomatosa y neoplasias. ${ }^{11}$

En el tejido, las colonias se agrupan para formar gránulos de azufre patognomónicos. Pueden presentar material intensamente eosinófilo en forma de estrella o radiación, alrededor de grupos de microorganismos, lo que se denomina fenómeno Splendore-Hoeppli. ${ }^{6}$

Requieren de una herida traumática o quirúrgica, presencia de cuerpos extraños, infecciones crónicas o recurrentes para establecerse. ${ }^{12}$ La infección mixta inicial es condicionante. Esto explica la presentación de diferentes casos en la literatura que detallan la larga historia de otomastoiditis que no han respondido al tratamiento médico. El potencial de oxidación-reducción es crítico para el desarrollo de la infección. ${ }^{4}$ A medida que avanza la infección, Actinomyces se establece como el patógeno predominante.

Existen tres características clínicas que deben hacer sospechar esta infección: ${ }^{10}$

1. La combinación de cronicidad e invasión, con progresión a través de las fronteras tisulares. Este rasgo puede ser explicado por la presencia de enzimas proteolíticas, que conducen a una extensa destrucción de los tejidos blandos y la penetración a través de los planos tisulares.

2. El desarrollo de un tracto fistuloso, que se puede resolver en forma espontánea y reaparecer posteriormente.

3. Comportamiento recidivante y resistente a ciclos cortos de tratamiento, que requiere antibioticoterapia prolongada.

Clínicamente, se caracteriza por una fase inflamatoria aguda tipo celulitis, única o múltiple. La piel adyacente toma un color rojo o azulado y la lesión evoluciona hacia la fluctuación y supuración central, con necrosis, infiltrado neutrófilo y formación de gránulos. La fase crónica se caracteriza por una lesión fibrótica y densa que se extiende en forma continua y lentamente progresiva en los planos tisulares.

Es notable que los tejidos comprometidos están indurados, relativamente avasculares y edematizados, y tienden a formar múltiples fístulas que supuran temprano y que, a veces, se cierran de modo espontáneo para volver a abrirse. Con el tiempo, los trayectos fistulosos se extienden hacia la piel, los órganos, el hueso o los tejidos adyacentes. ${ }^{13,14}$ 
El diagnóstico diferencial incluye neoplasias, enfermedades granulomatosas, como la tuberculosis, nocardiosis, histoplasmosis, coccidioidomicosis, criptococosis, blastomicosis y botriomicosis. ${ }^{10} \mathrm{El}$ diagnóstico preoperatorio correcto es inferior al $10 \%$ de los casos.

El diagnóstico es histológico por el aislamiento en cultivos. Deben incubarse, como mínimo, durante 2 semanas. El tratamiento quirúrgico incluye el drenaje de abscesos voluminosos, marsupialización, extirpación de la lesión fibrótica recalcitrante y / o el desbridamiento de tejido óseo necrótico en caso de osteomielitis.

La mayoría de los aislamientos son sensibles a betalactámicos, y el tratamiento de elección es un curso prolongado de amoxicilina oral. La penetración de los betalactámicos en el hueso es baja, por lo que el tratamiento puede incluir clindamicina, macrólidos y doxiciclina, que tienen una mejor penetración ósea.

El curso de tratamiento tradicional es de 6-12 meses. ${ }^{12-15}$ Puede acortarse si se realiza la resección quirúrgica de los tejidos infectados. Presenta favorable respuesta al tratamiento antibiótico instaurado y ausencia de afectación ósea. Se han informado tasas de curación satisfactorias con terapia antimicrobiana de 4 a 6 semanas en estos casos. ${ }^{5}$

La actinomicosis es una enfermedad poco frecuente que puede presentarse con características similares a una otitis media crónica complicada y no sospecharse en primera instancia. Una vez diagnosticada, debe instaurarse un tratamiento combinado prolongado.

\section{Agradecimientos}

Los autores agradecen a las licenciadas Mariana Niotti e Ingrid Klenner, quienes forman parte de la División de Otorrinolaringologia Infantil del Hospital General de Niños "Pedro de Elizalde", Sector de Audiología, por sus aportes y contribuciones en el diagnóstico del paciente.

\section{REFERENCIAS}

1. Thukral R, Shrivastav K, Mathur V, Barodiya A, et al. Actinomyces: a deceptive infection of oral cavity. J Korean Assoc Oral Maxilofac Surg. 2017; 43(4):282-5.

2. SugrueI, O'Connor PM, HillC, Stanton C, etal. Actinomyces Produces Defensin-Like Bacteriocins (Actifensins) with a Highly Degenerate Structure and Broad Antimicrobial Activity. J Bacteriol. 2020; 202(4):e00529-19.

3. Ajal M, Turner J, Fagan P, Walker P. Actinomycosis otomastoiditis. J Laryngol Otol. 1997; 111(11):1069-71.

4. Russmueller G, Seemann R, Weiss K, Stadler V, et al. The association of medication related osteonecrosis of the jaw with Actinomyces spp. infection. Sci Rep. 2016; 6:31604.

5. Valour F, Sénéchal A, Dupieux C, Karsenty J, et al. Actinomycosis: etiology, clinical features, diagnosis, treatment, and management. Infect Drug Resist. 2014; 7:18397.

6. Lezcano C, Simons JP, Colman KL, Cohen ML, et al. Actinomycotic mastoiditis complicated by sigmoid sinus thrombosis and labyrinthine fistula. Pediatr Dev Pathol. 2014; 17(6):478-81.

7. Boor A, Jurkovic I, Friedmann I, Benicictf $M$, et al. Actinomycosis of the middle ear. J Laryngol Otol. 1998; 112(8):800-1.

8. Prasad Chatterjee R, Shah N, Kundu S, Mahmud A, et al. Cervicofacial Actinomycosis Mimicking Osseous Neoplasm: A Rare Case. J Clin Diagn Res. 2015; 9(7):ZD2931.

9. Lancella A, Abbate G, Foscolo AM, Dosdegani R. Two unusual presentations of cervicofacial actinomycosis and review of the literatura. Acta Otorhinolaryngol Ital. 2008; 28(2):89-93

10. Vazquez Guillamet J, Malinis MG, Meyerc JP. Emerging role of Actinomyces meyeri in brain abscesses: A case report and literature review. IDCases. 2017; 10:26-9.

11. McHugh K, Sturgis C, Procop G, Rhoads D. The cytopathology of Actinomyces, Nocardia, and their mimickers. Diagn Cytopathol. 2017; 45(12):1105-15.

12. Könönen E, Wadec WG. Actinomyces and Related Organisms in Human Infections. Clin Microbiol Rev. 2015; 28(2):419-42.

13. Gajdács M, Urbán E, Terhes G. Microbiological and Clinical Aspects of Cervicofacial Actinomyces Infections: An Overview. Dent J (Basel). 2019; 7(3):85.

14. VásquezJ, Gómez C, Chiquillo A, Pescador L. Actinomicosis diseminada con compromiso de sistema nervioso central. Rev Chil Infectol. 2017; 34(6):598-602.

15. ShenJY, Futran ND, Sardesai MG. Craniofacial Actinomyces osteomyelitis evolving from sinusitis. Radiol Case Rep. 2017; 13(1):104-7. 